\title{
Impact of Multiple Recycling on the Strength of Coarse Aggregate
}

\author{
Afroja Sultana*,, Md. Roknuzzaman ${ }^{2}$, Aysha Afrose ${ }^{1}$, Tapti Dev ${ }^{1}$. \\ ${ }^{1}$ Graduate Student, Hajee Mohammad Danesh Science and Technology University, Dinajpur, Bangladesh \\ ${ }^{2}$ Assistant Professor, Hajee Mohammad Danesh Science and Technology University, Dinajpur, Bangladesh
}

\section{Keywords}

\section{Recycling,}

$R C A$,

Repeated Recycled Aggregate, Aggregated Crushing Value,

Green Concrete.

\begin{abstract}
Concrete structures are integral parts of modern civilization. Every year a huge amount of concrete waste is generated due to demolition of old concrete structures for replacing them with new high-rise buildings or other structures, which consequently, increasing the environmental loads. Recycling of demolished concrete is found to be an effective way for sustainable development which can also minimize the disposal problem associated with concrete waste. Recycling of demolished concrete to produce usable aggregate, therefore, has drawn attention of researchers in the field of concrete technology. However, most of the studies in this field are focused on $1^{\text {st }}$ generation recycled aggregate. Effect of multiple recycling on the properties of aggregate is merely studied. In this study, the effect of multiple times recycling on aggregate strength is observed. Strength of aggregate is evaluated in laboratory by Aggregate Crushing Value (ACV) test and Aggregate Impact Value (AIV) test after each generation of recycling. The ACV and AIV values of $1^{\text {st }}$ generation, $2^{\text {nd }}$ generation and $3^{\text {rd }}$ generation recycled aggregates are compared with the natural source aggregate. Strength degradation after each stage of recycling is recorded. In addition, the test results of $1^{\text {st }}$ generation, $2^{\text {nd }}$ generation and $3^{\text {rd }}$ generation recycled aggregates are interpreted, investigated and compared with standard requirement to outline their corresponding applications. ACV value for natural aggregate is found to increase by $2.5 \%$ after $1^{\text {st }}$ stage of recycling and it increased by $4.64 \%$ and $6.79 \%$ after $2^{\text {nd }}$ and $3^{\text {rd }}$ stage of recycling respectively. On the other hand, AIV value for natural aggregate is found to increase by $7.04 \%$ after $1^{\text {st }}$ stage of recycling and it increased by $10.35 \%$ and $12.47 \%$ after $2^{\text {nd }}$ and $3^{\text {rd }}$ stage of recycling respectively. The study reveals that the strength of $1^{\text {st }}$ generation recycled aggregates is quite similar to that of natural aggregate and can be used for concreting in general purposes. $2^{\text {nd }}$ generation recycled aggregate cannot be used in the production of concrete in heavy duty floor but can successfully be used in concrete for wearing surface and $3^{\text {rd }}$ generation recycled aggregates are too weak for road surfacing.
\end{abstract}

\section{Introduction}

Sustainable construction and infrastructural management largely depend on the recycling and reuse of construction and demolition (C\&D) waste. Unfortunately, the amount of C\&D waste is increasing every year. Among all the C\&D wastes, concrete waste occupies a significant portion. As their disposal is costly requiring large space in landfills, it is highly demanding to find a way to reuse them so that this huge amount of waste can be turned into a natural resource for construction industry. It is high time to find alternate use of such demolished concrete so as to protect our environment. One possible way of utilizing this concrete waste is to separate the ingredients like aggregate, reinforcing bars etc. and use them as ingredients for producing new concrete, which can lead to a greener environment and pave the way for sustainable construction. The consumption of natural aggregate is significantly increasing with the increased production and utilization of concrete in the construction sector Construction industry is one of the largest consumers of the natural aggregate. Every year 15 billion tons of concrete are produced throughout the world which means 2 tons of concrete per inhabitant per year [1]. In order to fulfill this huge demand, the sources of good quality natural aggregates are considerably declining all over the world. Each year ten to eleven billion tons of aggregate are being used all over the world [2]. Recycled aggregate concrete (RAC) is a relatively new construction material which is produced by crushing old concrete and using the demolished materials as aggregate replacement in new concrete. The aggregates extracted from old demolished concrete are said to be recycled aggregates. Its uses in construction industry may help in minimizing environmental problems such as in reducing the environment pollution, in preserving limited natural resources, in reducing the amount of space taken in landfills by concrete debris, in lessening freight costs due to lighter weights and in many more ways. Rather than producing concrete recycled aggregates have potentials to be used in highway construction and other purposes provided that their strength and other properties are within acceptable limits. Subsequently, when some recycled concrete gets older, they may need to be demolished again. This will regenerate further concrete waste, which has the potential for similar reuse. But at the same time aggregate properties may deteriorate with each cycle of reuse. Such property deterioration may make the recycled aggregate unfit for a particular usage. Therefore, recycled aggregate, extracted by repeated recycling is a competitive and innovative green product, which requires extensive experimental investigation as its utilization will lead us one step forward towards a more sustainable world. This research is intended to find out the possibility of using coarse aggregates extracted from demolished concrete and the main concern is to observe the deterioration of its strength with repeated number of recycling.

A lot of researchers all around the globe are found to be interested in finding solution for the disposal problem associated with construction waste and most of them are pointing toward recycling and reusing the waste. A research work involving extensive experimental programs is carried out aiming at examining the performance of Portland- 
cement concrete produced with natural and coarse recycled aggregates; it presents the suitability for use in a series of designated applications based on the effects of recycled concrete aggregate replacement (up to 100\%) on physical and engineering properties [3]. Another study focusing on the strength of recycled concrete as compared to that of the parent concrete is conducted with $33.33 \%$ recycled aggregate to produce new concrete with different water cement ratio and it is observed that strength reduction is more severe in case of high strength concrete [4]. Another approach to evaluate properties of recycled aggregate and concrete produced from those suggests that some simple and economical methods such as controlling the water-cement ratio, adjusting the aggregate moisture content and the different mixing method can improve the performance of recycled concrete in order to meet the requirement of concrete quality [5]. Many promising outcomes are presented in literatures. Study on high grade recycled concrete shows that an aggregate replacement rate of up to $40 \%$ of the coarse fraction has no detrimental effect on the mechanical and durability performance [6]. Possibility of using recycled aggregate concrete in pavement construction is presented in many literatures and it is found eventually promising $[6,7,8$, 9]. In a research on sustainable development of concrete technology, recycled aggregate collected from demolished 30-years old and 50-years old buildings are tested and the aggregates are found to have better abrasion resistance and absorption characteristics [10]. Vega et al. (2020) conducted life cycle assessment hot mix asphalt with recycled concrete aggregates for road pavements construction to investigate possible environmental deterioration and concluded that within certain limit of replacement, RCA can be considered as eco-friendly alternatives to the conventional mixture [11]. A case study on cost-benefit analysis of the production of ready-mixed high-performance concrete made with recycled concrete aggregate presented by Makul (2020) reveals that recycled concrete aggregate manufacturing set-ups can be used in the industrial-scale manufacture of recycled concrete and at low prices [12]. Seismic performance of recycled aggregate is also presented in literatures. A research confirmed that recycled concrete hollow block masonry walls could meet the seismic requirements through thoughtful design [13]. Masood et al. (2020) reported that the incorporation of bentonite with recycled aggregate concrete showed significant improvement in the durability and later strength [14]. All the above-mentioned outstanding researches indicate the importance of concrete recycling and recommend the use of recycled aggregates. However, most of the study and literatures are concerned with 1st generation recycled aggregate. Another interesting subject matter in this field may be the effect of repeated or multiple recycling and in this regard this study is very important to establish a guideline for concrete recycling and subsequent use of the recycled aggregate.

The present study aims to investigate the effect of repeated recycling on strength of aggregate said to be recycled concrete aggregate (RCA). Two important aggregates strength parameter such as Aggregate Crushing Value (ACV) and Aggregate Impact Value (AIV) are chosen as indicator of aggregate strength. The properties are tested in laboratory following standard procedures and the test results are compared with standard requirement so as to suggest potential use of recycled aggregate after each generation of recycling.

\section{Materials and methodology}

The study evaluates the performance of 1 st, 2 nd and 3rd generation of recycled concrete made with $100 \%$ recycled concrete aggregate (RCA) and compares them with that of natural coarse aggregate (NCA). The 1st generation of recycled aggregate $(A)$ is produced by the demolition of matured concrete cube made of NCA. The 2nd generation RCA (B) is produced by demolishing the matured concrete cubes made of $1^{\text {st }}$ generation RCA and the 3rd generation RCA (C) is produced by demolishing the matured concrete cubes made of $2^{\text {nd }}$ generation RCA. As quality of aggregate is found to be degraded a lot at $3^{\text {rd }}$ generation RCA, no further recycling is considered.

The research work followed the flow diagram as shown in Fig. 1

\subsection{Materials and their sources}

Materials involved this study are the concrete ingredients namely coarse aggregate, fine aggregate, binding material and water. All the materials are sourced locally from Dinajpur region, Bangladesh. A list of materials is presented in Table 1.

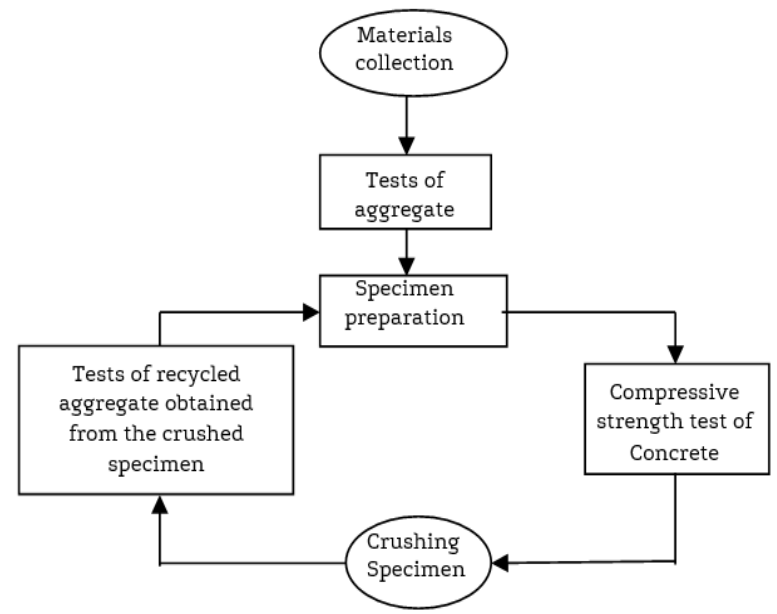

Figure 1. Flow diagram of evolution process of recycled concrete made with repeated recycled coarse aggregate.

Table 1. Materials and their sources

\begin{tabular}{|c|c|c|c|}
\hline $\begin{array}{c}\text { Serial } \\
\text { No. }\end{array}$ & $\begin{array}{c}\text { Material } \\
\text { Name }\end{array}$ & Material Type & Source/Origin \\
\hline 1 & $\begin{array}{l}\text { Coarse } \\
\text { Aggregate }\end{array}$ & Crushed Stone & $\begin{array}{l}\text { Panchagarh, } \\
\text { Bangladesh }\end{array}$ \\
\hline 2 & $\begin{array}{l}\text { Fine } \\
\text { Aggregate }\end{array}$ & Coarse Sand & $\begin{array}{l}\text { Nilphamary, } \\
\text { Bangladesh }\end{array}$ \\
\hline 3 & $\begin{array}{l}\text { Binding } \\
\text { Material }\end{array}$ & $\begin{array}{l}\text { Ordinary } \\
\text { Portland Cement } \\
\text { (CEM-I) }\end{array}$ & $\begin{array}{c}\text { Premier Cement } \\
\text { Mills, } \\
\text { Munshiganj, } \\
\text { Bangladesh }\end{array}$ \\
\hline 4 & Water & Potable Water & Laboratory Tap \\
\hline
\end{tabular}

\subsection{Test standards}

A series of laboratory tests are carried out on NCA as well as RCA maintaining the standard procedures as presented in Table 2.

Table 2. Test properties and test standards

\begin{tabular}{clc}
\hline $\begin{array}{c}\text { Serial } \\
\text { No. }\end{array}$ & \multicolumn{1}{c}{ Test Name } & Test Standards \\
\hline 1 & $\begin{array}{l}\text { Sieve Analysis } \\
\text { Aggregate crushing value test } \\
\text { of coarse aggregate }\end{array}$ & ASTM C136 \\
2 & $\begin{array}{l}\text { Aggregate impact value test of } \\
\text { coarse aggregate }\end{array}$ & BS 812-112:1990 \\
3 & $\begin{array}{l}\text { Compressive strength test of } \\
\text { concrete }\end{array}$ & ASTM C39/C39M \\
\hline
\end{tabular}

\subsection{Preparation of concrete specimen}

A Typical mix proportion 1:2:4 (cement: fine aggregate: coarse aggregate) is adopted with a $60 \%$ water-cement ratio. Properties of ingredients used for concreting and mix related data are presented below:

- $\quad$ FM of sand: 2.56 (Tested by ASTM C136)

- Gradation of Coarse aggregate: $19 \mathrm{~mm}$ to $9.5 \mathrm{~mm}$ (as required in ASTM C33)

- Mix proportion: 1:2:4 (Cement: Sand: NCA/RCA)

- Water Cement Ratio: 0.60 (For all cases)

- Mixing Technique: Hand Mixing 
Required quantities of $150 \mathrm{~mm}$ cubical specimens are prepared. For crushing strength referencing purpose, 6 standard cylinder specimen of size $150 \mathrm{~mm}$ in diameter and $300 \mathrm{~mm}$ in height are also prepared for each batch.

\subsection{Extraction of recycled aggregated}

After 28 days' water curing the specimens made with NCA are taken out and crushed primarily by using universal testing machine. Further manual hammer crushing is applied to obtain usable $1^{\text {st }}$ generation recycled aggregate (A) from the demolished concrete. Sieve analysis is made to separate the aggregates to be used for concreting in next phase. A fraction of the recycled aggregate (A) is tested for strength evaluation in the same procedure as conducted for the natural aggregate. In the similar manner concreting is done using the $1^{\text {st }}$ generation aggregate maintaining same proportion and parameters, cured for 28 days and crushed to produce $2^{\text {nd }}$ generation recycled aggregate $(B)$ and thereby the third generation of repeated recycled aggregate $(C)$. Strength tests are conducted for $2^{\text {nd }}$ and $3^{\text {rd }}$ generation recycled aggregates. Different generation of recycled aggregate is shown in Fig. 2

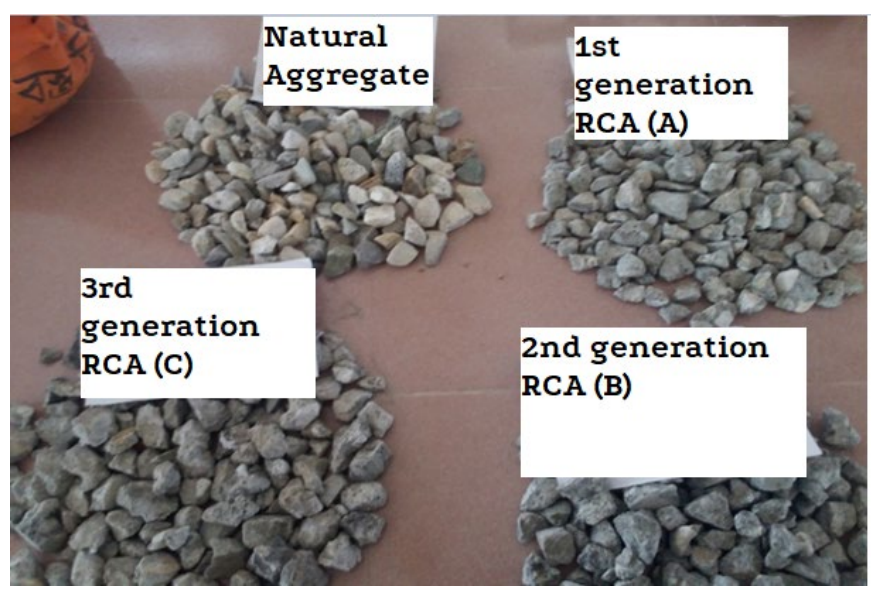

Figure 2. Different Generation of Recycled Aggregate

\subsection{Testing of specimens and aggregates}

Concrete cube and cylinder specimens are tested for compressive strength by crushing them using a Universal Testing Machine (CONTROLS). The natural source aggregate and extracted recycled aggregates are tested for ACV and AIV with standard apparatus.

\section{Results and discussions}

\subsection{Aggregate Crushing Value test}

The results of Aggregate Crushing Value (ACV) test for NCA, $1^{\text {st }}$ generation RCA, $2^{\text {nd }}$ generation RCA and $3^{\text {rd }}$ generation RCA are represented in the following bar chart (Fig. 3). The chart shows the percentage of ACV for natural aggregate as $22.00 \%$ which is increased after every stage of recycling becoming $24.50 \%, 26.64 \%$ and $28.79 \%$ for sample $1^{\text {st }}, 2^{\text {nd }}$ and $3^{\text {rd }}$ generation RCA respectively. ACV value increased with each stage of recycling as aggregates are stressed in hardened concrete. A $5 \%$ rise of ACV value for $1^{\text {st }}$ generation RCA is reported in literature [15].

The results indicate that all aggregate samples passed the British Standard's ACV specified requirement to be not more than $35 \%$. The standard also specifies that $\mathrm{ACV}<25 \%$ aggregates can be used in the production of concrete in heavy duty floor and $25 \%<\mathrm{ACV}<45 \%$ aggregates can be used in concrete for wearing surfaces. Therefore, from ACV point of view, the first two samples can be used for production of concrete in heavy duty floor and sample B and C can be used in concrete for wearing surface.

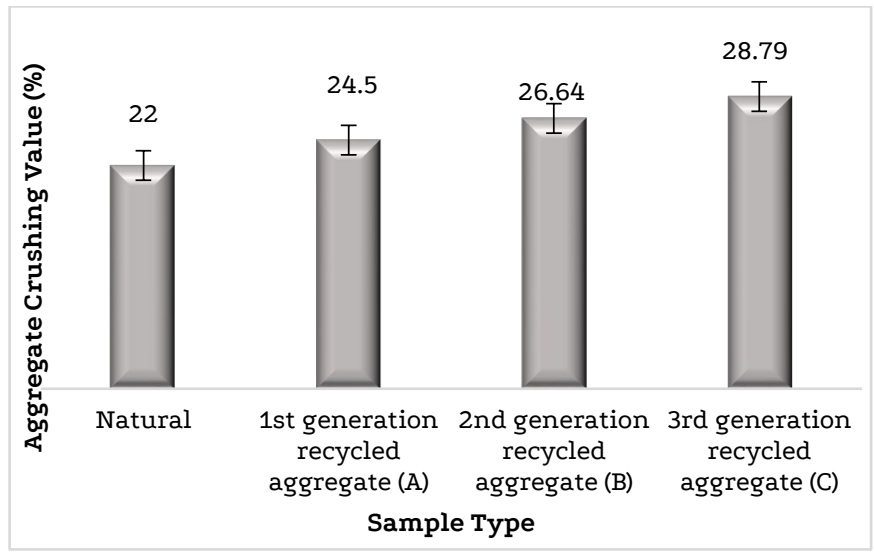

Figure 3. Aggregate crushing value (ACV) for different generation of RCA

\subsection{Aggregate Impact Value test}

The values of aggregate impact test for natural aggregate and recycled aggregates are presented in the following bar chart (Fig. 4).

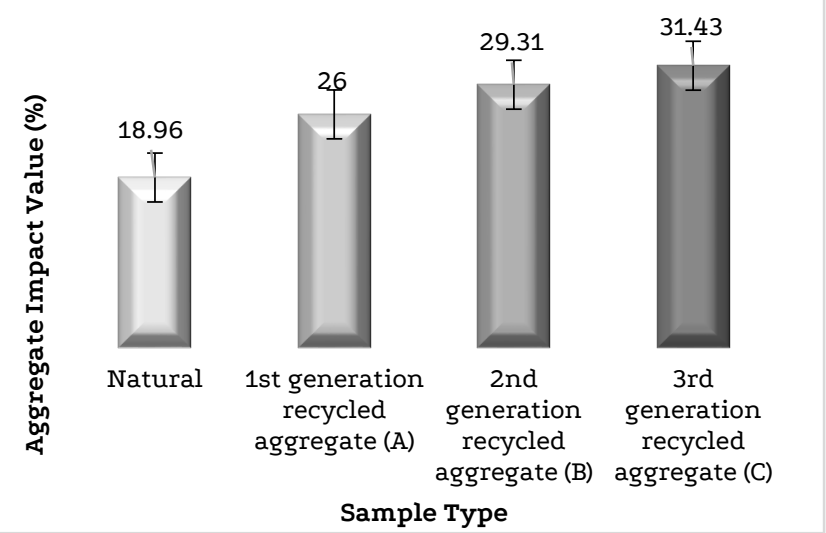

Figure 4. Aggregate impact value (AIV) for different generation of RCA

The AIV for natural aggregate is $18.96 \%$ which is increased after every stage of recycling. The value is increased to $26.00 \%, 29.31 \%$ and $31.43 \%$ for $1^{\text {st }}, 2^{\text {nd }}$, and $3^{\text {rd }}$ generation RCA respectively. AIV value increases in case of RCA as the aggregates are stressed in hardened concrete and also, they are disturbed during extraction process. AIV up to $20 \%$ indicates strong aggregates and AIV up to $30 \%$ is found to be satisfactory for road surfacing [11]. The test results indicate that sample A and B can be used in concrete for wearing surface. But sample $\mathrm{C}$ exceeds the limit $30 \%$ and it is weak for road surfacing.

\subsection{Compressive strength of concrete}

The values of compressive strength (both cube and cylinder) of concrete made with natural aggregate and recycled aggregates are tabulated below in Table 3.

Table 3. Result of compressive strength of concrete

\begin{tabular}{cccc}
\hline $\begin{array}{c}\text { Serial } \\
\text { Number }\end{array}$ & $\begin{array}{c}\text { Type of } \\
\text { aggregate }\end{array}$ & $\begin{array}{c}\text { Cube strength } \\
\text { (Average of 6 } \\
\text { specimen) } \\
(\mathrm{MPa})\end{array}$ & $\begin{array}{c}\text { Cylindrical } \\
\text { strength (Average } \\
\text { of 6 specimen) } \\
(\mathrm{MPa})\end{array}$ \\
\hline 1 & $\begin{array}{c}\text { Natural } \\
1^{\text {st }}\end{array}$ & 38.72 & 27.10 \\
2 & $\begin{array}{c}\text { Generation } \\
\text { RCA } \\
2^{\text {nd }}\end{array}$ & 34.57 & 24.20 \\
& $\begin{array}{c}\text { Generation } \\
\text { RCA }\end{array}$ & 21.82 & 15.27 \\
\hline
\end{tabular}


Table 3 shows the variation of compressive strength among the three concrete mixes produced with NCA, $1^{\text {st }}$ generation RCA and $2^{\text {n }}$ generation RCA. As compressive strength is heavily degraded for specimen with $2^{\text {nd }}$ generation RCA, further test with $3^{\text {rd }}$ generation RCA is not considered. As aggregate strength is reduced in case of subsequent RCA, concrete strength is also reduced. Similar observation was made by Sivakumar et al. (2014) [15]. The test results indicate that the concrete compressive strength for $1^{\text {st }}$ generation RCA is not much differing with the natural one so it can be effectively used for general purpose. But the concrete made using the $2^{\text {nd }}$ generation RCA has much lower strength and cannot withstand higher loads.

\section{Conclusions}

The present study reveals the effect of multiple recycling on a source aggregate. The results can be used as a reference for using the aggregates in different purposes after each stage of recycling. The ACV and AIV results clearly indicate a trend of decreasing strength with each phase of recycling. From ACV consideration, all of the recycled aggregates, i.e. $1^{\text {st }}, 2^{\text {nd }}$ and $3^{\text {rd }}$ generation with ACV $24.5 \%$, $26.64 \%$ and $28.79 \%$, can be used for road surfacing. But the AIV result rejects the possibility of using $3^{\text {rd }}$ generation RCA for road surfacing as it has AIV 31.43\% which is more than specified 30\%. Also, concrete strength test indicates a lesser strength for $2^{\text {nd }}$ generation RCA which is only $21.82 \mathrm{MPa}$ as compared to its parent concrete with strength $38.72 \mathrm{MPa}$. As stated in earlier literatures, $1^{\text {st }}$ generation $\mathrm{RCA}$, therefore, can be used for general concreting purposes and the $2^{\text {nd }}$ generation RCA may be used for road surfacing. $3^{\text {rd }}$ and subsequent generation RCA should not be used for pavement surfacing because of their low AIV. However, the present study is focused on a particular type of source aggregate with sufficiently strong ACV value. Furthe studies on source aggregates with varying ACV value may be considered to observe the trend of strength degradation. Also, some pre-treatment of aggregate such as acid emersion may also be incorporated in order to get better results

\section{Acknowledgements}

Sincere thanks and gratitude are due for Engr. Md. Ariful Islam, workshop civil Technology, Dinajpur Polytechnic Institute, Dinajpur and Engr. Md. Aktaruzzman, Executive Engineer, Local Government Engineering Department, Rangpur for their assistance. Authors acknowledge the assistance of Rana Sarker, Undergraduate student, HSTU, Dinajpur for supporting throughout the research work.

\section{Declaration of Conflict of Interests}

The authors declare that there is no conflict of interest. They have no known competing financial interests or personal relationships that could have appeared to influence the work reported in this paper.

\section{References}

[1.] Huda S.B., and Alam, M.S., Mechanical behavior of three generations of $100 \%$ repeated recycled coarse aggregate concrete, Construction and Building Materials, 65(2014), 574-582.

[2.] Smith, J.T., Recycled concrete aggregate-a viable aggregate source for concrete pavements, PhD Dissertation, Department of Civil Engineering, University of Waterloo, Waterloo, ON, Canada, (2010).

[3.] Limbachiya, M.C., Koulouris, A., Roberts, J.J., and Fried, A.N., Performance of recycled aggregate concrete, In Proceeding of RILEM International Symposium on Environment-Conscious Materials and Systems for Sustainable Development, (2004), 127136.

[4.] Hossain, M.B., Islam, M.R., and Roknuzzaman, M., Effect of parent concrete strength on the strength of Recycled Aggregate Concrete, Journal of Science and Technology, 15(2017), 34-39.
[5.] Bai G., Zhu C., Liu C., and Liu B., An evaluation of the recycled aggregate characteristics and the recycled aggregate concrete mechanical properties, Construction and Building Materials, 240(2020), 117978

[6.] Kox S., Vanroelen G., Van Herck J., De Krem H., and Vandoren B. Experimental evaluation of the high-grade properties of recycled concrete aggregates and their application in concrete road pavement construction, Case Studies in Construction Materials, 11(2019), e00282.

[7.] Poongodi K., Murthi P., Gobinath R., Srinivas A., and Sangeetha G. Mechanical properties of pavement quality concrete using recycled aggregate, Int. J. Innov. Technol. Exploring Eng., 9.1(2019), 33-38.

[8.] Chan R., Santana M.A., Oda A.M., Paniguel R.C., Vieira L.B., Figueiredo A.D., and Galobardes I., Analysis of potential use of fibre reinforced recycled aggregate concrete for sustainable pavements, Journal of Cleaner Production, 218(2019), 183-191.

[9.] Busari A., Adeyanju E., Loto T., and Ademola D., Recycled aggregate in pavement construction: review of literatures, In Journal of Physics: Conference Series, 1378.2(2019), 022026, IOP Publishing.

[10.] Mohammed T.U., Bangladesh-Sustainable development of concrete technology, In Proceedings of the CBM-CI-International Workshop (2007), 249-267.

[11.] Vega A D.L., Santos J., and Martinez-Arguelles G., Life cycle assessment of hot mix asphalt with recycled concrete aggregates for road pavements construction. International Journal of Pavement Engineering, 16(2020), 1-4.

[12.] Makul N., Cost-benefit analysis of the production of ready-mixed high-performance concrete made with recycled concrete aggregate: A case study in Thailand, Heliyon, 6.6(2020), e04135.

[13.] Liu C., Nong X., Zhang F., Quan Z., and Bai G., Experimental study on the seismic performance of recycled concrete hollow block masonry walls, Applied Sciences, 9.20 (2019), 4336.

[14.] Masood B., Elahi A., Barbhuiya S., and Ali B., Mechanical and durability performance of recycled aggregate concrete incorporating low calcium bentonite, Construction and Building Materials, 237(2020), 117760.

[15.] Uche O.A., Influence of recycled concrete aggregate (RCA) on compressive strength of plain concrete, Pan, 8.2(2008), 0-17.

[16.] Sivakumar N., Muthukumar S., Sivakumar V., Gowtham D., and Muthuraj V., Experimental studies on high strength concrete by using recycled coarse aggregate, International Journal of Engineering and Science, 4.1(2014), 27-36.

\section{How to Cite This Article}

Sultana, A., Roknuzzaman, M., Afrose, A., and Dev, T., Impact of Multiple Recycling on the Strength of Coarse Aggregate, Civil Engineering Beyond Limits, 1(2021),12-15.

https://doi.org/10.36937/cebel.2021.001.003 